\title{
Effect of Alkyltrimethylammonium Ions on Corrosion and Electrochemical Behavior of Pb-Ca-Sn Alloy
}

\author{
Kacper Kopczyński ${ }^{1}$, Agnieszka Gabryelczyk ${ }^{1}$, Marek Baraniak ${ }^{1}$, Bartosz Lęgosz ${ }^{1}$, \\ Juliusz Pernak ${ }^{1}$, Pawet Kędzior ${ }^{2}$, Grzegorz Lota ${ }^{1, *}$ \\ ${ }^{1}$ Faculty of Chemical Technology, Poznan University of Technology, Berdychowo 4, 60-965 Poznan, \\ Poland \\ ${ }^{2}$ PPUH AUTOPART Jacek Bąk Sp. z o.o., Kwiatkowskiego 2a, 39-300 Mielec, Poland \\ *E-mail: grzegorz.lota@put.poznan.pl
}

doi: $10.20964 / 2018.11 .85$

Received: 7 July 2018 / Accepted: 23 August 2018 / Published: 1 October 2018

\begin{abstract}
Due to the increasing competition on the chemical power sources market, lead-acid batteries must improve their parameters and functionality. A modification of electrolyte composition is suggested in the presented paper for better corrosion inhibition and enhancement of the stability of the sulfuric acidbased electrolyte during charging process. Ten quaternary ammonium-based ionic liquids have been employed as additives to electrolyte. The differences between used compounds have been based on different types of anion in the molecule (sulfate and bisulfate) and the length of the substituent incorporated in the cation. The electrochemical window of the electrolyte in terms of onset potentials of hydrogen and oxygen evolution reactions, corrosion potential, corrosion current density and polarization resistance of the alloy in case of corrosion have been the parameters evaluated based on the undertaken experiments. It has been noted that the length of the side chain in the molecule has a great impact on the final properties of ionic liquids. Experiments have shown that hexadecyltrimethylammonium-based ionic liquids contributed to the most visible improvement in comparison to the other compounds. Significance of the anion in the molecule has been also observed, bisulfate anion appeared to be beneficial for the overall performance of the lead-calcium-tin alloy electrode.
\end{abstract}

Keywords: Ionic liquids; corrosion; current collector; lead alloy; lead-acid battery

\section{$\underline{\text { FULL TEXT }}$}

(C) 2018 The Authors. Published by ESG (www.electrochemsci.org). This article is an open access article distributed under the terms and conditions of the Creative Commons Attribution license (http://creativecommons.org/licenses/by/4.0/). 